\title{
Metformin and the intestine
}

\author{
C. J. Bailey • C. Wilcock • J. H. B. Scarpello
}

Received: 24 April 2008 /Accepted: 24 April 2008 / Published online: 5 June 2008

(C) Springer-Verlag 2008

Keywords Antihyperglycaemic · Intestine - Lactate · Metformin

To the Editor: The antihyperglycaemic effect of metformin is generally attributed to a decrease in hepatic glucose output, with some additional effects that increase peripheral glucose uptake and utilisation [1]. The intestine also makes an important contribution to the glucose-lowering effect of metformin, but this is often overlooked because of a paucity of clinical data [2]. Animal studies indicate that metformin can cause intestinal glucose absorption to be delayed and occur more distally along the tract [3, 4]. However, animal studies have also shown that metformin increases glucose utilisation by the intestine, particularly anaerobic glucose metabolism [5-7], and this contributes to an apparent shortfall in the passage of glucose from the luminal to the serosal side of the intestine [3]. Extra lactate delivered into the portal vein is at least partly converted into glucose, increasing glucose turnover after administration of metfor$\min [5,7,8]$. We demonstrate here that metformin increases lactate production in human intestinal mucosa, similar to reports in animal studies.

Animal studies have long established that very high concentrations of metformin accumulate in the wall of the

\section{J. Bailey $(\bowtie) \cdot$ C. Wilcock}

School of Life and Health Sciences, Aston University,

Birmingham B4 7ET, UK

e-mail: c.j.bailey@aston.ac.uk

J. H. B. Scarpello

Department of Diabetes and Endocrinology,

University Hospital of North Staffordshire NHS Trust,

Stoke-on-Trent, UK intestine [9], which may at least partly explain the increase in anaerobic metabolism. We provide confirmatory evidence herein that similarly high concentrations of metformin accumulate in the human intestinal mucosa.

In the present study, eight recently diagnosed, drug-naive, obese type 2 diabetic patients [five men, three women; age $55 \pm 3$ years (mean \pm SEM); BMI $\left.33 \pm 1 \mathrm{~kg} / \mathrm{m}^{2}\right]$ attended on three occasions after an overnight fast. Patients gave informed consent, and ethical approval was granted by the research ethics committee. A venous blood sample was taken for plasma glucose assay (automated glucose oxidase method), and a mucosal biopsy sample (approximately $25 \mathrm{mg}$ ) was taken on each occasion from the proximal jejunum, under light midazolam sedation, using an adapted paediatric gastroscope. On the first occasion, tissue was washed, divided into two portions, weighed and then incubated for $2 \mathrm{~h}$ at $37^{\circ} \mathrm{C}$ in $1 \mathrm{ml}$ of Krebs Ringer bicarbonate buffer supplemented with $20 \mathrm{mg} / \mathrm{ml}$ serum albumin, $10 \mathrm{mmol} / 1$ glucose, $10^{-8} \mathrm{~mol} / 1$ insulin with or without $10^{-3} \mathrm{~mol} / 1 \mathrm{metformin}$ hydrochloride, and maintained in an atmosphere of $95 \% \mathrm{O}_{2}, 5 \% \mathrm{CO}_{2}[4,5]$. Lactate production was measured as the concentration of lactate in the medium (manual spectrophotometric method). Metformin therapy was initiated at a dosage of $850 \mathrm{mg}$ once daily and titrated up to twice daily after 2-3 weeks. Two repeat proximal jejunal mucosal biopsies were obtained after 6-8 weeks of therapy. A pre-dose sample was obtained in the morning, 12-16 h after the last metformin tablet (taken the evening before), and a post-dose sample was taken $3 \mathrm{~h}$ after the morning tablet. Tissue samples were washed in buffered saline, blotted and weighed, and then metformin was extracted with acetonitrile and assayed by gas chromatography [10].

The results showed that incubation of the jejunal biopsy tissue with $10^{-3} \mathrm{~mol} / \mathrm{l}$ metformin increased lactate produc- 
tion by $35 \%\left[64.1 \pm 8.6 \mathrm{vs} 86.9 \pm 12.0 \mu \mathrm{mol} \mathrm{g}^{-1} 2 \mathrm{~h}^{-1}\right.$ (mean \pm $\mathrm{SEM}), p<0.05)$. Treatment with metformin for 6 weeks reduced fasting plasma glucose from $11.8 \pm 1.0$ to $8.7 \pm$ $1.0 \mathrm{mmol} / \mathrm{l}(p<0.01)$, without changing body weight. The metformin concentration in the pre-dose jejunal samples obtained $12-16 \mathrm{~h}$ after the last $850 \mathrm{mg}$ dose was $33 \pm 26 \mathrm{ng} / \mathrm{mg}$ wet weight of tissue (approximately $250 \mu \mathrm{mol} / \mathrm{kg}$ ) compared with $504 \pm 232 \mathrm{ng} / \mathrm{mg}$ wet weight of tissue (approximately $4 \mathrm{mmol} / \mathrm{kg}$ ) in the post-dose sample obtained $3 \mathrm{~h}$ after the last $850 \mathrm{mg}$ dose $(p<0.01)$. The concentration of metformin in the jejunum was about 30-300 times higher than plasma concentrations (pre- dose $<1.0 \mu \mathrm{g} / \mathrm{ml}[<8 \mu \mathrm{mol} / \mathrm{l}]$ and postdose $1-3 \mu \mathrm{g} / \mathrm{ml}(8-24 \mu \mathrm{mol} / \mathrm{l})]$ [10].

The present observations substantiate the hypothesis that metformin is accumulated in the mucosa of the human intestine at much higher concentrations than in plasma. Since metformin concentrations in the intestinal mucosa are also much higher than in other tissues [9], it is anticipated that the drug will have different effects in this tissue [2], notably in terms of increasing anaerobic metabolism to lactate [5-7]. Preclinical studies have shown that metformin does not cause a net increase in lactate production in a selection of other tissues, including muscle, fat, brain and skin $[4,5]$. Thus, consistent with preclinical evidence $[6,7]$, the human intestine appears to be an important source of metformin-induced lactate production. This also supports other clinical and animal evidence that metformin-associated increases in lactate concentrations typically emerge during meal absorption $[1,2]$. In preclinical studies, the intestinal effects of metformin have been shown to increase glucose turnover and contribute to the antihyperglycaemic effect $[6,7]$. The cycling of lactate back to glucose can occur in part in the liver, but animal studies indicate that raised lactate concentrations in the presence of raised glucose concentrations are associated with net lactate utilisation in the periphery, because lactate concentrations are slightly lower in the inferior vena cava than arterial blood $[5,8]$.
From a clinical perspective, it should be re-emphasised that small postprandial increases in plasma lactate during metformin therapy are usually within the normal range $(<2 \mathrm{mmol} / \mathrm{l})$ and can be dealt with efficiently by normal body metabolism. Metformin-associated lactic acidosis is rare $(<0.1$ and probably about 0.03 per 1,000 patient-years of treatment) [1]. Such cases are invariably linked to inappropriate use of the drug when a contraindication, especially renal insufficiency, has been overlooked [1, 2], emphasising that contraindications must always be respected.

Duality of interest The authors declare that there is no duality of interest associated with this manuscript.

\section{References}

1. Bailey CJ, Turner RC (1996) Metformin. N Engl J Med 334:574-579

2. Bailey CJ, Campbell IW, Chan JCN et al (eds) (2007) Metformin: the gold standard. Wiley, Chichester

3. Wilcock C, Bailey CJ (1990) Reconsideration of inhibitory effect of metformin on intestinal glucose absorption. J Pharm Pharmacol 43:120-121

4. Wilcock C, Bailey CJ (1990) Sites of metformin-stimulated glucose metabolism. Biochem Pharmacol 39:1831-1834

5. Bailey CJ, Wilcock C, Day C (1992) Effect of metformin on glucose metabolism in the splanchnic bed. $\mathrm{Br} \mathrm{J}$ Pharmacol 105:1009-1013

6. Bailey CJ, Mynett KJ, Page T (1994) Importance of the intestine as a site of metformin-stimulated glucose utilization. $\mathrm{Br} \mathrm{J}$ Pharmacol 112:671-675

7. Penicaud L, Hitier Y, Ferre P, Girard J (1989) Hypoglycaemic effect of metformin in genetically obese (fa/fa) rats results from an increased utilization of blood glucose by intestine. Biochem J 262:881-885

8. Radziuk J, Bailey CJ, Wiernsperger NF, Yudkin JS (2003) Metformin and its liver targets in the treatment of type 2 diabetes. Current Drug Targets 3:151-169

9. Wilcock C, Bailey CJ (1994) Accumulation of metformin by tissues of normal and diabetic mice. Xenobiotica 24:49-57

10. Tucker GT, Casey C, Phillips PJ et al (1981) Metformin kinetics in healthy subjects and in patients with diabetes mellitus. Br J Clin Pharmacol 12:235-2466 